\title{
Shared mechanisms in stemness and carcinogenesis: lessons from oncogenic viruses
}

\section{Demetris lacovides, Stella Michael ${ }^{\dagger}$, Charis Achilleos $^{\dagger}$ and Katerina Strati ${ }^{*}$}

Department of Biological Sciences, University of Cyprus, Nicosia, Cyprus

\section{Edited by:}

Dominique Ferrandon, Centre

National de la Recherche

Scientifique, France

Reviewed by:

Jean-Marie Peloponese, Centre

National de la Recherche

Scientifique, France

Dohun Pyeon, University of

Colorado School of Medicine, USA

\section{*Correspondence:}

Katerina Strati, Department of

Biological Sciences, University of

Cyprus, 1 University Avenue, 2109

Nicosia, Cyprus

e-mail: strati@ucy.ac.cy

these authors have contributed

equally to this work.
A rise in technologies for epigenetic reprogramming of cells to pluripotency, highlights the potential of understanding and manipulating cellular plasticity in unprecedented ways. Increasing evidence points to shared mechanisms between cellular reprogramming and the carcinogenic process, with the emerging possibility to harness these parallels in future therapeutics. In this review, we present a synopsis of recent work from oncogenic viruses which contributes to this body of knowledge, establishing a nexus between infection, cancer, and stemness.

Keywords: cancer, stemness, reprogramming, HBV, HCV, HPV, EBV, KSHV

\section{INTRODUCTION}

Long-standing observations have noted a number of parallels between the homeostasis of cancer cells and that of stem cells. A complicated picture includes the involvement of tissue stem cells as the cells-of-origin for some cancers, a stem cell compartment thought to maintain most tumors [commonly known as cancer stem cells (CSCs)], as well as more recent concepts of differentiated cells being reprogrammed back to pluripotency during the carcinogenic process (Lapouge et al., 2011; Friedmann-Morvinski et al., 2012). Several publications have shown that classic tumor suppressors such as $\mathrm{p} 53$ and $\mathrm{pRb}$ have emerging roles in the regulation of stemness (Conklin and Sage, 2009; Bonizzi et al., 2012). In addition to that, genes generally known for their key roles in stem cell biology, for example Nanog, appear to be deregulated in a number of cancers (Zhang et al., 2012; Lu et al., 2013). In the cutting edge field of reprogramming cells to pluripotency, key players in tumor suppression have been implicated in crucial roadblocks to the reprogramming process. While there is still a lot to be understood, it has been proposed that understanding the complicated relationship between stemness and cancer may hold the key to more successful future therapies; for example targeting cancer stem cells may reduce the possibility of future cancer recurrence.

Virally-induced cancers, thought to account for about $20 \%$ of the global cancer incidence, have long been studied to enable better understanding of the clinical manifestation of the disease as well as for their value as models of carcinogenesis overall (Farrell, 2002). Such cancers are attributed mainly to Hepatitis B Virus (HBV), Hepatitis C Virus (HCV), Human Papilloma Virus (HPV), Epstein-Barr Virus (EBV), Kaposi's Sarcoma-associated Herpes virus (KSHV), Human T-cell Leukemia Virus-1 (HTLV1), and more recently, Merkel Cell Polyoma Virus (MCPyV)
(Samanta et al., 2003; Bonilla Guerrero and Roberts, 2005; Bajaj et al., 2007; Schiffman et al., 2007; Saha et al., 2010; Jeong et al., 2012; Amber et al., 2013; Cook et al., 2013). These viruses encode proteins shown to impinge on various cellular processes including cell cycle regulation, apoptosis, cell signaling, transcriptional regulation, and epigenetic regulation, resulting in carcinogenesis (Saha et al., 2010). We present here evidence which implicates oncogenic viruses in the regulation of pluripotency at various levels. We argue that virus-associated cancers can serve as models to understand the general link between cancer and stemness, as well as the distinct role that infection plays in these cases. It should be noted that other types of infectious agents, most notably the leprosy bacterium and Helicobacter pylori, have also been shown to modulate stemness-associated processes and pathways in host cells, raising the possibility that strategies involving the manipulation of cellular stemness may serve as evolutionary advantages to pathogens (Fujii et al., 2012; Wegner, 2013). Here, we review the available evidence for regulation of stemness by oncogenic viruses with particular emphasis on results coming from in vivo model systems. We also propose key questions that remain to be addressed.

\section{INTERACTION OF ONCOGENIC VIRUSES WITH TISSUE STEM CELLS}

Tissue stem cells and committed tissue progenitor cells destined for terminal differentiation are target cells of several oncogenic viruses. While no known oncogenic virus displays exclusive tropism for such specific cell populations, infection of either a stem or progenitor population may provide the opportunity of a longer-lived cellular reservoir for viral replication. In addition, infection of these cells might in some cases enable viruses to evade the immune system, since tissue progenitor/stem cells might be 
immune privileged (Di Trapani et al., 2013), even though this notion is still controversial (Tseng et al., 2010).

Gammaherpesviruses, including KSHV and its murine cousin MHV68 and EBV infect primarily resting mature B cells. However, these cells are short-lived and non-proliferating, which points to the possibility that herpesviruses may also be able to infect a progenitor, stem cell-like population of B cells, which normally gives rise to mature B cells, in order to ensure continuous viral genome propagation and viral latency maintenance. Indeed, there is some evidence that both human and murine gammaherpesviruses infect hematopoetic progenitor cells. KSHV has been detected in immature hematopoetic cells in the bone marrow of transplant recipients (Luppi et al., 2000; Lapouge et al., 2011) and in hematopoietic progenitor cells in Kaposi's sarcoma patients (Henry et al., 1999; Friedmann-Morvinski et al., 2012), whereas MHV68 was detected in immature splenic B cells in the mouse (Marques et al., 2003; Collins et al., 2009). Moreover, KSHVinfected human hematopoietic progenitor stem cells gave rise to KSHV-infected mature human B-cells and monocytes when transplanted in NOD/SCID mice (Wu et al., 2006). Coleman et al. examined developing B cell infection by MHV68, a model for gammaherpesviruses, in a fully immunocompetent mouse host. They showed that this virus establishes long-term latency in immature B cells in the bone marrow as well as in transitional B cells in the spleen (Coleman et al., 2010). Since these self-renewing stem cell populations of developing $B$ cells give rise to mature resting $\mathrm{B}$ cells, the authors speculate that infection of these cell populations by herpesviruses might play a key role in the maintenance of lifelong infection in the host.

Even though the direct involvement of Human Cytomegalovirus (HCMV) in tumor initiation is still not well-documented, a variety of malignancies have been associated with HCMV infections and persistence but the association is more widely accepted for malignant gliomas (Harkins et al., 2002; Samanta et al., 2003; Soderberg-Naucler, 2006; Michaelis et al., 2009). In normal brain tissue, HCMV appears to primarily target cells in the subventricular zone (SVZ) of the brain (Perlman and Argyle, 1992; Fritschy et al., 1996; Odeberg et al., 2007), which is the source of local stem cells and progenitor cells within this organ (Seri et al., 2006). Differentiation of neural precursors into mature neurons seems to reduce susceptibility to HCMV infection (Lokensgard et al., 1999; Cheeran et al., 2005) and activation of PDGFR alpha (essential to the self-renewal potential of neural stem cells) (Kofman et al., 2011) by HCMV is necessary for successful infection (Soroceanu et al., 2008). These results further support the possibility that the primary cell reservoir for HCMV, at least in the brain, is the stem cell compartment (Dziurzynski et al., 2012), and that infection of HCMV of this cell population might be a way for the virus to successfully establish lifelong latency in the host.

HPVs are strongly associated with a number of malignancies, most notably cervical carcinoma (CC). Several studies have proposed the existence of multiple HPV target cells within the host epithelium. There is increasing support for the hypothesis that stem cells of the transformation zone (TZ) of the cervical epithelium are the primary site of persistent HPV infection (Lopez et al., 2012). Given the anatomical observation that a lot of cervical cancers are derived from the TZ, a connection between infection of tissue stem cells and eventual carcinogenesis has been proposed. The long latency period between infection with HPV and development of cervical dysplasias supports the hypothesis that these cells can be targets of HPV infection and serve as a vehicle for long-term established viral latency in the cervix. Using laser capture microdissection in a rabbit oral papillomavirus (ROPV) model system, Maglennon et al. (2011) showed that ROPV indeed persists in a latent state, even after immune-mediated regression of induced papillomas, and that the site of latency is a subset of basal epithelial cells which the authors propose are the epithelial stem cells. It should be noted that expression of papillomavirus genes in stem cells has been shown to modulate their behavior in vivo and may be associated with ensuing carcinogenesis. In a study using mice transgenic for the HPV16 oncogenes our group showed that expression of viral oncogenes in label-retaining epithelial stem cells caused aberrant mobilization (Michael et al., 2013). In a related study, using animals expressing the entire HPV16 viral genome in all basal cells of stratified epithelia, skin cancers were shown to derive from tissue stem cells (da Silva-Diz et al., 2013).

\section{VIRUSES GIVING RISE TO CANCER STEM CELLS}

CSCs are cells within a tumor that possess stem cell properties, namely the ability to self-renew and give rise to progeny destined for differentiation to regenerate tumor cell diversity. Though genetic changes or oncogenic infection of an undifferentiated cell is usually thought to give rise to tumor initiating cells, tumors have been shown to originate from differentiated cells as well (Friedmann-Morvinski et al., 2012). It has been suggested that cellular reprogramming mediated by oncogenic viruses may promote the formation of tumor initiating cells or CSCs. The term "tumor initiating cells," strictly referring to the initial cells from which a tumorigenic transformation occurs, is used interchangeably in most cases, describing the ability of CSCs to fully regenerate, or "reinitiate" the tumor.

Several reports have implicated oncogenic viruses in the generation of CSCs. Arzumanyan et al. recently showed that HBV might induce initiation of hepatocellular carcinomas (HCC) by activating cellular factors that promote stemness (Arzumanyan et al., 2011). HBV encoded $\mathrm{X}$ antigen $(\mathrm{HBVx})$, important in the viral life cycle as well as carcinogenesis, was shown to activate stemness associated factors Oct-4, Nanog, Klf4, beta catenin, and EpCAM in vitro. In addition, this protein was shown to induce cell migration, sphere formation, and growth in soft agar, all phenotypic characteristics of CSCs. These results were confirmed in liver biopsies obtained from HCC patients, since the above stemness associated markers were observed in the majority of HBV associated HCCs (Arzumanyan et al., 2011). Interestingly, microarray data from $\mathrm{HBV}$-associated $\mathrm{HCC}$ showed that miR-181, recently found to contribute to tumorigenesis (Agami, 2010), was over-expressed in hematopoietic stem cells (HSCs) and CSCs, and was also found to be upregulated in $\mathrm{HBx}$ expressing cells and $\mathrm{HBx}$-positive liver biopsies (Arzumanyan et al., 2011) suggesting that this micro-RNA might be involved in stemness or CSCs induction and maintenance in HBV-associated HCCs. 
The HCV has also been implicated in induction of CSCs. Machida et al. isolated tumor initiating stem-like cells from transgenic mice expressing $\mathrm{HCV}$ core, as well as from patients with HCC, and showed that the Tlr4-Nanog pathway was upregulated in these cells and was necessary for their tumorigenic properties (Machida et al., 2009, 2012). Nanog, a stem/progenitor cell marker was further shown to be upregulated through activation of the TLR4 pathway by NS5A, a non-structural protein encoded by HCV (Machida et al., 2012). Furthermore, a study by Ali et al. showed that infection of cultured hepatic cells with an HCV subgenomic replicon resulted in acquisition of CSC characteristics, including expression of Lgr5, c-myc, and DCAMKL-1 (Ali et al., 2011). A DCAMKL-1 enriched cell population was subsequently shown to form tumors with expression of proteins associated with metastatic potential in athymic nude mice. Importantly, removing the HCV replicon from these cells dramatically reduced expression of the stem cell-associated markers. The results correlated well with analysis of liver biopsies from HCV-infected patients, further highlighting the possibility that $\mathrm{HCV}$ promotes a CSC-like phenotype in vivo.

Several studies have suggested the possibility that EBV might exert its tumorigenic properties at least in part by giving rise to CSCs within the infected tissue. In an important study, Kong et al. investigated the role of EBV LMP2A protein in CSC modulation in nasopharyngeal carcinoma (NPC) cells, and showed that expression of this protein induced cell invasion and epithelial-mesenchymal transformation (EMT) (Kong et al., 2010). Overexpression of LMP2A was found to enrich stem cell like cells within the NPC tumor cell population, and increased the number of cells that were capable of re-establishing tumors in nude mice (Kong et al., 2010). These results were subsequently confirmed in NPC patient biopsies, further suggesting that a possible mechanism of tumorigenesis in EBV-infected tissues is the modulation of the tissue stem cell compartment and the induction of tumor initiating cancer stem cells. A subsequent study showed that, similar to LMP2A, EBV encoded LMP1 latent membrane protein also stimulated EMT, induced a CSC/CPC-like phenotype and enhanced the self-renewal potential in nasopharyngeal epithelial cell lines, further supporting EBV involvement in modulation of cellular plasticity and induction of CSC cellular phenotypes (Kondo et al., 2011). This notion is also highlighted by a more recent study (Lun et al., 2012), which showed up-regulation of multiple stem cell markers in an EBV-positive NPC cell line with increased tumorigenic potential and high resistance to chemotherapy. Finally, a recent study by Port et al. demonstrated that NPC is frequently associated with deregulation of the Hedgehog $(\mathrm{HH})$ pathway, a pathway that is associated with stem cell maintenance. In an in vitro model of NPC, the authors showed that EBV activates the $\mathrm{HH}$ pathway through induction of the $\mathrm{SHH}$ ligand, which leads to increased expression of stemness-associated genes and induction of stem cell phenotypes in these cells (Port et al., 2013).

The long length of papillomavirus infection usually preceding malignant pathologies has been proposed to relate to latency of viral infection in tissue stem cells. Infected tissue stem cells may serve as tumor initiating or CSC in HPV-induced CCs. In support of this hypothesis, a study showed that the invasive and metastatic potential of cervical squamous cell carcinoma (CSCC) was correlated with cancer stem cell-associated genes, and supported the idea that high-risk HPV might induce CSC phenotypes in the TZ of the cervical epithelium (Liu et al., 2010). In addition, expression of HPV E6 and E7 viral oncogenes was shown to induce epigenetic reprogramming in human keratinocytes, through modulation of chromatin structure and global methylation/acetylation events involving cellular factors that have significant role in tumorigenesis and stemness. For example, Hyland et al. showed that E6/E7-expressing primary human foreskin keratinocytes have elevated levels of the EZH2 methyltransferase and the KDM6A demethylase, which results in a reduction of global $\mathrm{H} 3 \mathrm{~K} 27$ trimethylation and upregulation of downstream targeted HOX genes (Hyland et al., 2011). Reduction in trimethylation of H3K27 associated with elevated EZH2 was also demonstrated in high-grade squamous cervical intraepithelial lesions. In a related study, McLaughlin et al. demonstrated that repressive $\mathrm{H} 3 \mathrm{~K} 27$ trimethylation was reduced in HPV-positive cervical lesions, and that this was a result of E7-mediated induction of KDM6A and KDM6B demethylases, which subsequently lead to significantly higher expression of homeobox genes (McLaughlin-Drubin et al., 2011). These findings support the possibility that HPV-induced epigenetic reprogramming is important in viral oncogenesis, and further highlight the commonalities between stemness and carcinogenesis, at least in the context of the oncogenic virus life cycle. Further research is needed to fully understand whether HPV-associated cancers are related to cellular reprogramming of infected tissue stem cells or more differentiated cells. The impact of such reprogramming on the viral life cycle also remains unknown.

\section{PATHWAYS TARGETED BY ONCOGENIC VIRUSES ARE ASSOCIATED WITH STEMNESS}

A number of reports have shown that classic tumor suppressors and their pathways, notably p53 and pRb, which are long known to be targets of oncogenic viruses (Felsani et al., 2006; Levine, 2009), have important roles in modulation of stemness.

The p53/ARF pathway is a well-established stemness repressor and cells in which this pathway is inactivated can be more efficiently reprogrammed to pluripotency (Hanna et al., 2009; Hong et al., 2009; Kawamura et al., 2009; Li et al., 2009; Marion et al., 2009; Utikal et al., 2009). p53 was also recently found to induce miR-34a and miR-145, which negatively regulate stemness-associated factors ( $\mathrm{Xu}$ et al., 2009; Jain et al., 2012). More recently, two separate reports further highlighted the importance of p53 in stem cell biology. Chiche et al. showed that somatic loss of $\mathrm{p} 53$ resulted in higher numbers of stem/progenitor cells in mammary epithelium (Chiche et al., 2013). Sato et al. reported that p53 activation promoted proteosome-dependent degradation of Nanog and differentiation of glioma stem cells (Sato et al., 2013). It is therefore possible that p53 inactivation, a common strategy of oncogenic viruses, may contribute positively to the viral life cycle in a way additional to the proposed viral escape of apoptosis of infected cells. 


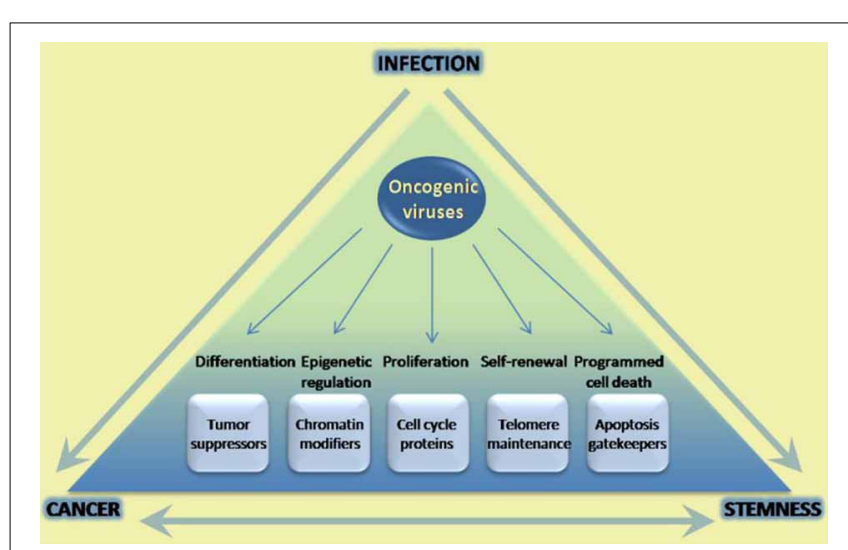

FIGURE 1 | Infection with oncogenic viruses highlights parallels in cancer and stem cell biology. Oncogenic viruses modulate a variety of cellular pathways with parallel roles in the carcinogenic process and stem cell homeostasis. The parallels between these two processes have been extensively documented, and increasingly well-understood in terms of being able to reprogram cell state. However little has been done in the way of uncovering potential roles of these pathways in infection success. Increasing understanding of common pathways modulated may yield better tools to prevent and treat infection, as well as ensuing carcinogenesis.

The retinoblastoma tumor suppressor $(\mathrm{pRb})$ is another major target of oncogenic viruses, since inhibition of $\mathrm{Rb}$ liberates the E2F transcription factor, which stimulates entry of the cell into the cell cycle, thus favoring viral replication. Increasing evidence has implicated this pathway in stemness modulation, initially in plants (Ebel et al., 2004; Wildwater et al., 2005) and subsequently in animals (Liu et al., 2009). Accumulating evidence reinforces the role of pRb in stem cell homeostasis (Conklin and Sage, 2009). The $\mathrm{pRb}$ pathway was shown to have a critical role as a roadblock in the reprogramming of human fibroblasts to iPSCs, as well as cell fate determination, as elegantly shown by Calo et al. (2010). Conceivably then, like p53 inactivation, the inactivation of $\mathrm{pRb}$ could promote cellular plasticity and stemness, which in turn would confer an ideal niche for virus persistence and latency.

There is mounting evidence supporting the recently suggested notion that tumor suppressor pathways, traditionally key targets of oncogenic viruses, might play a significant role in cellular plasticity and modulation of stemness. Even cellular factors activated by genetic events in virally-induced cancers such as c-myc in Burkitt's lymphoma, have well-described involvement in cancer as well as stemness (Dang, 2012; Buganim et al., 2013). Therefore, it is also not surprising that factors traditionally involved in stemness and cellular plasticity are increasingly being identified as targets of oncogenic viruses. Indeed, HCV, HBV, and EBV have been shown to regulate a number of pluripotency and stem cellassociated factors (Ruf et al., 1999; Machida et al., 2009; Ali et al., 2011; Lun et al., 2012). In addition, telomerase activation and telomere maintenance are important in both cancer and stemness, and it is therefore not surprising that oncogenic viruses evolved to regulate these processes. Most, if not all, tumor viruses, including the oncogenic retrovirus HTLV-1, induce transcriptional activation of telomerase (Kuhlmann et al., 2007; Bellon and Nicot, 2008), and EBV and HPV are also known to regulate telomerase post-transcriptionally.

\section{DISCUSSION}

Oncogenic viruses cause cancer after long-term infection of their natural niche. These viruses interfere with signaling pathways that are important in a number of major cellular processes including cell proliferation and cell division, apoptosis, and cell differentiation. Accumulating evidence suggests that oncogenic viruses may also manipulate cellular stemness in various ways. Stem cells or progenitor cells are targets of infection and normal cell homeostasis is disrupted as a result. Moreover, pathways that are traditionally associated with self-renewal and lineagecommitment have been shown to be transcriptionally regulated by viral oncoproteins. Regulation of such pathways, and of oncogenic pathways now understood to play key roles in stemness, may lead to cellular reprogramming. Whether regulation of stemness is necessary for ensuing carcinogenesis, or whether it has any impact on the viral life cycle, has not been conclusively addressed. However, it is conceivable that infection of tissue stem cells might positively affect the viral life cycle, especially in terms of establishing a successful chronic infection (Figure 1). It should also be noted that regulation of innate immunity and inflammation, also known to be linked to carcinogenesis, is now beginning to be linked to stemness as well (e.g., TLR4-Nanog, TLR3) (Machida et al., 2009; Lee et al., 2012). Additional studies are necessary in order to fully investigate this notion, especially in the context of in vivo infection models. As we continue to explore the parallels between cellular stemness and the carcinogenic process, oncogenic viruses continue to serve as excellent paradigms with plenty to teach.

\section{REFERENCES}

Agami, R. (2010). microRNAs, RNA binding proteins and cancer. Eur. J. Clin. Invest. 40, 370-374. doi: 10.1111/j.1365-2362.2010.02279.x

Ali, N., Allam, H., May, R., Sureban, S. M., Bronze, M. S., Bader, T., et al. (2011). Hepatitis C virus-induced cancer stem cell-like signatures in cell culture and murine tumor xenografts. J. Virol. 85, 12292-12303. doi: 10.1128/JVI.05920-11

Amber, K., McLeod, M. P., and Nouri, K. (2013). The merkel cell polyomavirus and its involvement in merkel cell carcinoma. Dermatol. Surg. 39, 232-238. doi: 10.1111/dsu. 12079

Arzumanyan, A., Friedman, T., Ng, I. O., Clayton, M. M., Lian, Z., and Feitelson, M. A. (2011). Does the hepatitis B antigen HBx promote the appearance of liver cancer stem cells? Cancer Res. 71, 3701-3708. doi: 10.1158/0008-5472.CAN-103951

Bajaj, B. G., Murakami, M., and Robertson, E. S. (2007). Molecular biology of EBV in relationship to AIDS-associated oncogenesis. Cancer Treat. Res. 133, 141-162. doi: $10.1007 / 978-0-387-46816-7 \_5$

Bellon, M., and Nicot, C. (2008). Regulation of telomerase and telomeres: human tumor viruses take control. J. Natl. Cancer Inst. 100, 98-108. doi: 10.1093/jnci/djm269

Bonilla Guerrero, R., and Roberts, L. R. (2005). The role of hepatitis B virus integrations in the pathogenesis of human hepatocellular carcinoma. J. Hepatol. 42, 760-777. doi: 10.1016/j.jhep.2005.02.005

Bonizzi, G., Cicalese, A., Insinga, A., and Pelicci, P. G. (2012). The emerging role of p53 in stem cells. Trends Mol. Med. 18, 6-12. doi: 10.1016/j.molmed.2011.08.002

Buganim, Y., Faddah, D. A., and Jaenisch, R. (2013). Mechanisms and models of somatic cell reprogramming. Nat. Rev. Genet. 14, 427-439. doi: $10.1038 / \operatorname{nrg} 3473$

Calo, E., Quintero-Estades, J. A., Danielian, P. S., Nedelcu, S., Berman, S. D., and Lees, J. A. (2010). Rb regulates fate choice and lineage commitment in vivo. Nature 466, 1110-1114. doi: 10.1038/nature09264 
Cheeran, M. C., Hu, S., Ni, H. T., Sheng, W., Palmquist, J. M., Peterson, P. K., et al. (2005). Neural precursor cell susceptibility to human cytomegalovirus diverges along glial or neuronal differentiation pathways. J. Neurosci. Res. 82, 839-850. doi: 10.1002/jnr.20682

Chiche, A., Moumen, M., Petit, V., Jonkers, J., Medina, D., Deugnier, M. A., et al. (2013). Somatic loss of P53 leads to Stem/Progenitor cell amplification in both mammary epithelial compartments, basal and luminal. Stem Cells 9, 1857-1867. doi: 10.1002/stem.1429

Coleman, C. B., Nealy, M. S., and Tibbetts, S. A. (2010). Immature and transitional B cells are latency reservoirs for a gammaherpesvirus. J. Virol. 84, 13045-13052. doi: 10.1128/JVI.01455-10

Collins, C. M., Boss, J. M., and Speck, S. H. (2009). Identification of infected B-cell populations by using a recombinant murine gammaherpesvirus 68 expressing a fluorescent protein. J. Virol. 83, 6484-6493. doi: 10.1128/JVI.00297-09

Conklin, J. F., and Sage, J. (2009). Keeping an eye on retinoblastoma control of human embryonic stem cells. J. Cell. Biochem. 108, 1023-1030. doi: 10.1002/jcb.22342

Cook, L. B., Elemans, M., Rowan, A. G., and Asquith, B. (2013). HTLV-1: persistence and pathogenesis. Virology 435, 131-140. doi: 10.1016/j.virol.2012.09.028

Dang, C. V. (2012). MYC on the path to cancer. Cell 149, 22-35. doi: 10.1016/j.cell.2012.03.003

da Silva-Diz, V., Sole-Sanchez, S., Valdes-Gutierrez, A., Urpi, M., Riba-Artes, D., Penin, R. M., et al. (2013). Progeny of Lgr5-expressing hair follicle stem cell contributes to papillomavirus-induced tumor development in epidermis. Oncogene 32, 3732-3743. doi: 10.1038/onc.2012.375

Di Trapani, M., Bassi, G., Ricciardi, M., Fontana, E., Bifari, F., Pacelli, L., et al. (2013). Comparative study of immune regulatory properties of stem cells derived from different tissues. Stem Cells Dev. 22, 2990-3002. doi: $10.1089 /$ scd.2013.0204

Dziurzynski, K., Chang, S. M., Heimberger, A. B., Kalejta, R. F., McGregor Dallas, S. R., Smit, M., et al. (2012). Consensus on the role of human cytomegalovirus in glioblastoma. Neuro Oncol. 14, 246-255. doi: 10.1093/neuonc/nor227

Ebel, C., Mariconti, L., and Gruissem, W. (2004). Plant retinoblastoma homologues control nuclear proliferation in the female gametophyte. Nature 429, 776-780. doi: $10.1038 /$ nature02637

Farrell, P. J. (2002). Tumour viruses-could they be an achilles' heel of cancer? Eur. J. Cancer 38, 1815-1816. doi: 10.1016/S0959-8049(02)00241-1

Felsani, A., Mileo, A. M., and Paggi, M. G. (2006). Retinoblastoma family proteins as key targets of the small DNA virus oncoproteins. Oncogene 25, 5277-5285. doi: 10.1038/sj.onc. 1209621

Friedmann-Morvinski, D., Bushong, E. A., Ke, E., Soda, Y., Marumoto, T., Singer, O., et al. (2012). Dedifferentiation of neurons and astrocytes by oncogenes can induce gliomas in mice. Science 338, 1080-1084. doi: 10.1126/science.1226929

Fritschy, J. M., Brandner, S., Aguzzi, A., Koedood, M., Luscher, B., and Mitchell, P. J. (1996). Brain cell type specificity and gliosis-induced activation of the human cytomegalovirus immediate-early promoter in transgenic mice. J. Neurosci. 16, 2275-2282.

Fujii, Y., Yoshihashi, K., Suzuki, H., Tsutsumi, S., Mutoh, H., Maeda, S., et al. (2012). CDX1 confers intestinal phenotype on gastric epithelial cells via induction of stemness-associated reprogramming factors SALL4 and KLF5. Proc. Natl. Acad. Sci. U.S.A. 109, 20584-20589. doi: 10.1073/pnas.1208651109

Hanna, J., Saha, K., Pando, B., van Zon, J., Lengner, C. J., Creyghton, M. P., et al. (2009). Direct cell reprogramming is a stochastic process amenable to acceleration. Nature 462, 595-601. doi: 10.1038/nature08592

Harkins, L., Volk, A. L., Samanta, M., Mikolaenko, I., Britt, W. J., Bland, K. I., et al. (2002). Specific localisation of human cytomegalovirus nucleic acids and proteins in human colorectal cancer. Lancet 360, 1557-1563. doi: 10.1016/S01406736(02)11524-8

Henry, M., Uthman, A., Geusau, A., Rieger, A., Furci, L., Lazzarin, A., et al. (1999). Infection of circulating CD34+ cells by HHV-8 in patients with kaposi's sarcoma. J. Invest. Dermatol. 113, 613-616. doi: 10.1046/j.1523-1747.1999.00733.x

Hong, H., Takahashi, K., Ichisaka, T., Aoi, T., Kanagawa, O., Nakagawa, M., et al. (2009). Suppression of induced pluripotent stem cell generation by the p53-p21 pathway. Nature. 460, 1132-1135. doi: 10.1038/nature08235

Hyland, P. L., McDade, S. S., McCloskey, R., Dickson, G. J., Arthur, K., McCance, D. J., et al. (2011). Evidence for alteration of EZH2, BMI1, and KDM6A and epigenetic reprogramming in human papillomavirus type $16 \mathrm{E} 6 / \mathrm{E} 7$-expressing keratinocytes. J. Virol. 85, 10999-11006. doi: 10.1128/JVI.00160-11
Jain, A. K., Allton, K., Iacovino, M., Mahen, E., Milczarek, R. J., Zwaka, T. P., et al. (2012). p53 regulates cell cycle and microRNAs to promote differentiation of human embryonic stem cells. PLoS Biol. 10:e1001268. doi: 10.1371/journal.pbio. 1001268

Jeong, S. W., Jang, J. Y., and Chung, R. T. (2012). Hepatitis C virus and hepatocarcinogenesis. Clin. Mol. Hepatol. 18, 347-356. doi: 10.3350/cmh.2012.18.4.347

Kawamura, T., Suzuki, J., Wang, Y. V., Menendez, S., Morera, L. B., Raya, A., et al. (2009). Linking the p53 tumour suppressor pathway to somatic cell reprogramming. Nature 460, 1140-1144. doi: 10.1038/nature08311

Kofman, A., Marcinkiewicz, L., Dupart, E., Lyshchev, A., Martynov, B., Ryndin, A., et al. (2011). The roles of viruses in brain tumor initiation and oncomodulation. J. Neurooncol. 105, 451-466. doi: 10.1007/s11060-011-0658-6

Kondo, S., Wakisaka, N., Muramatsu, M., Zen, Y., Endo, K., Murono, S., et al. (2011). Epstein-barr virus latent membrane protein 1 induces cancer stem/progenitor-like cells in nasopharyngeal epithelial cell lines. J. Virol. 85, 11255-11264. doi: 10.1128/JVI.00188-11

Kong, Q. L., Hu, L. J., Cao, J. Y., Huang, Y. J., Xu, L. H., Liang, Y., et al. (2010). Epstein-barr virus-encoded LMP2A induces an epithelial-mesenchymal transition and increases the number of side population stem-like cancer cells in nasopharyngeal carcinoma. PLoS Pathog. 6:e1000940. doi: 10.1371/journal.ppat. 1000940

Kuhlmann, A. S., Villaudy, J., Gazzolo, L., Castellazzi, M., Mesnard, J. M., and Duc Dodon, M. (2007). HTLV-1 HBZ cooperates with JunD to enhance transcription of the human telomerase reverse transcriptase gene (hTERT). Retrovirology 4:92. doi: 10.1186/1742-4690-4-92

Lapouge, G., Youssef, K. K., Vokaer, B., Achouri, Y., Michaux, C., Sotiropoulou, P. A., et al. (2011). Identifying the cellular origin of squamous skin tumors. Proc. Natl. Acad. Sci. U.S.A. 108, 7431-7436. doi: 10.1073/pnas.1012720108

Lee, J., Sayed, N., Hunter, A., Au, K. F., Wong, W. H., Mocarski, E. S., et al. (2012). Activation of innate immunity is required for efficient nuclear reprogramming. Cell 151, 547-558. doi: 10.1016/j.cell.2012.09.034

Levine, A. J. (2009). The common mechanisms of transformation by the small DNA tumor viruses: the inactivation of tumor suppressor gene products: P53. Virology 384, 285-293. doi: 10.1016/j.virol.2008.09.034

Li, H., Collado, M., Villasante, A., Strati, K., Ortega, S., Canamero, M., et al. (2009). The Ink4/Arf locus is a barrier for iPS cell reprogramming. Nature 460, 1136-1139. doi: 10.1038/nature08290

Liu, W. K., Jiang, X. Y., and Zhang, Z. X. (2010). Expression of PSCA, PIWIL1 and TBX2 and its correlation with HPV16 infection in formalin-fixed, paraffinembedded cervical squamous cell carcinoma specimens. Arch. Virol. 155, 657-663. doi: 10.1007/s00705-010-0635-y

Liu, Y., Clem, B., Zuba-Surma, E. K., El-Naggar, S., Telang, S., Jenson, A. B., et al. (2009). Mouse fibroblasts lacking RB1 function form spheres and undergo reprogramming to a cancer stem cell phenotype. Cell Stem Cell 4, 336-347. doi: 10.1016/j.stem.2009.02.015

Lokensgard, J. R., Cheeran, M. C., Gekker, G., Hu, S., Chao, C. C., and Peterson, P. K. (1999). Human cytomegalovirus replication and modulation of apoptosis in astrocytes. J. Hum. Virol. 2, 91-101.

Lopez, J., Ruiz, G., Organista-Nava, J., Gariglio, P., and Garcia-Carranca, A. (2012). Human papillomavirus infections and cancer stem cells of tumors from the uterine cervix. Open Virol. J. 6, 232-240. doi: 10.2174/187435790120 6010232

Lu, X., Mazur, S. J., Lin, T., Appella, E., and Xu, Y. (2013). The pluripotency factor nanog promotes breast cancer tumorigenesis and metastasis. Oncogene. doi: 10.1038/onc.2013.209. [Epub ahead of print].

Lun, S. W., Cheung, S. T., Cheung, P. F., To, K. F., Woo, J. K., Choy, K. W., et al. (2012). CD44+ cancer stem-like cells in EBV-associated nasopharyngeal carcinoma. PLoS ONE 7:e52426. doi: 10.1371/journal.pone.0052426

Luppi, M., Barozzi, P., Schulz, T. F., Setti, G., Staskus, K., Trovato, R., et al. (2000). Bone marrow failure associated with human herpesvirus 8 infection after transplantation. N. Engl. J. Med. 343, 1378-1385. doi: 10.1056/NEJM200011093431905

Machida, K., Chen, C. L., Liu, J. C., Kashiwabara, C., Feldman, D., French, S. W., et al. (2012). Cancer stem cells generated by alcohol, diabetes, and hepatitis C virus. J. Gastroenterol. Hepatol. 27(Suppl. 2), 19-22. doi: 10.1111/j.14401746.2011.07010.x

Machida, K., Tsukamoto, H., Mkrtchyan, H., Duan, L., Dynnyk, A., Liu, H. M., et al. (2009). Toll-like receptor 4 mediates synergism between alcohol and HCV 
in hepatic oncogenesis involving stem cell marker nanog. Proc. Natl. Acad. Sci. U.S.A. 106, 1548-1553. doi: 10.1073/pnas.0807390106

Maglennon, G. A., McIntosh, P., and Doorbar, J. (2011). Persistence of viral DNA in the epithelial basal layer suggests a model for papillomavirus latency following immune regression. Virology 414, 153-163. doi: 10.1016/j.virol.2011.03.019

Marion, R. M., Strati, K., Li, H., Murga, M., Blanco, R., Ortega, S., et al. (2009). A p53-mediated DNA damage response limits reprogramming to ensure iPS cell genomic integrity. Nature 460, 1149-1153. doi: 10.1038/nature08287

Marques, S., Efstathiou, S., Smith, K. G., Haury, M., and Simas, J. P. (2003). Selective gene expression of latent murine gammaherpesvirus 68 in B lymphocytes. J. Virol. 77, 7308-7318. doi: 10.1128/JVI.77.13.73087318.2003

McLaughlin-Drubin, M. E., Crum, C. P., and Münger, K. (2011). Human papillomavirus E7 oncoprotein induces KDM6A and KDM6B histone demethylase expression and causes epigenetic reprogramming. Proc. Natl. Acad. Sci. U.S.A. 108, 2130-2135. doi: 10.1073/pnas.1009933108

Michael, S., Lambert, P. F., and Strati, K. (2013). The HPV16 oncogenes cause aberrant stem cell mobilization. Virology 443, 210-225. doi: 10.1016/j.virol.2013.04.008

Michaelis, M., Doerr, H. W., Cinatl, J. (2009). The story of human cytomegalovirus and cancer: increasing evidence and open questions. Neoplasia 11, 1-9. doi: $10.1593 /$ neo.81178

Odeberg, J., Wolmer, N., Falci, S., Westgren, M., Sundtrom, E., Seiger, A., et al. (2007). Late human cytomegalovirus (HCMV) proteins inhibit differentiation of human neural precursor cells into astrocytes. J. Neurosci. Res. 85, 583-593. doi: $10.1002 /$ jnr.21144

Perlman, J. M., and Argyle, C. (1992). Lethal cytomegalovirus infection in preterm infants: clinical, radiological, and neuropathological findings. Ann. Neurol. 31, 64-68. doi: 10.1002/ana.410310112

Port, R. J., Pinheiro-Maia, S., Hu, C., Arrand, J. R., Wei, W., Young, L. S., et al. (2013). Epstein-barr virus induction of the hedgehog signalling pathway imposes a stem cell phenotype on human epithelial cells. J. Pathol. 231, 367-377. doi: $10.1002 /$ path.4245

Ruf, I. K., Rhyne, P. W., Yang, H., Borza, C. M., Hutt-Fletcher, L. M., Cleveland, J. L., et al. (1999). Epstein-barr virus regulates c-MYC, apoptosis, and tumorigenicity in burkitt lymphoma. Mol. Cell. Biol. 19, $1651-1660$.

Saha, A., Kaul, R., Murakami, M., and Robertson, E. S. (2010). Tumor viruses and cancer biology: modulating signaling pathways for therapeutic intervention. Cancer Biol. Ther. 10, 961-978. doi: 10.4161/cbt.10.10.13923

Samanta, M., Harkins, L., Klemm, K., Britt, W. J., and Cobbs, C. S. (2003). High prevalence of human cytomegalovirus in prostatic intraepithelial neoplasia and prostatic carcinoma. J. Urol. 170, 998-1002. doi: 10.1097/01.ju.0000080263.46164.97

Sato, A., Okada, M., Shibuya, K., Watanabe, E., Seino, S., Suzuki, K., et al. (2013). Resveratrol promotes proteasome-dependent degradation of nanog via p53 activation and induces differentiation of glioma stem cells. Stem Cell Res. 11, 601-610. doi: 10.1016/j.scr.2013.04.004

Schiffman, M., Castle, P. E., Jeronimo, J., Rodriguez, A. C., and Wacholder, S. (2007). Human papillomavirus and cervical cancer. Lancet 370, 890-907. doi: 10.1016/S0140-6736(07)61416-0
Seri, B., Herrera, D. G., Gritti, A., Ferron, S., Collado, L., Vescovi, A., et al. (2006). Composition and organization of the SCZ: a large germinal layer containing neural stem cells in the adult mammalian brain. Cereb. Cortex 16(Suppl. 1), i103-il11. doi: 10.1093/cercor/bhk027

Soderberg-Naucler, C. (2006). Does cytomegalovirus play a causative role in the development of various inflammatory diseases and cancer? J. Intern. Med. 259, 219-246. doi: 10.1111/j.1365-2796.2006.01618.x

Soroceanu, L., Akhavan, A., and Cobbs, C. S. (2008). Platelet-derived growth factor-alpha receptor activation is required for human cytomegalovirus infection. Nature 455, 391-395. doi: 10.1038/nature07209

Tseng, H. C., Arasteh, A., Paranjpe, A., Teruel, A., Yang, W., Behel, A., et al. (2010). Increased lysis of stem cells but not their differentiated cells by natural killer cells; de-differentiation or reprogramming activates NK cells. PLoS ONE 5:e11590. doi: 10.1371/journal.pone.0011590

Utikal, J., Polo, J. M., Stadtfeld, M., Maherali, N., Kulalert, W., Walsh, R. M., et al. (2009). Immortalization eliminates a roadblock during cellular reprogramming into iPS cells. Nature 460, 1145-1148. doi: 10.1038/nature08285

Wegner, M. (2013). Mighty bugs: leprosy bacteria turn schwann cells into stem cells. Cell 152(1-2), 15-6. doi: 10.1016/j.cell.2013.01.001

Wildwater, M., Campilho, A., Perez-Perez, J. M., Heidstra, R., Blilou, I., Korthout, H., et al. (2005). The RETINOBLASTOMA-RELATED gene regulates stem cell maintenance in arabidopsis roots. Cell 123, 1337-1349. doi: 10.1016/j.cell.2005.09.042

Wu, W., Vieira, J., Fiore, N., Banerjee, P., Sieburg, M., Rochford, R., et al. (2006). KSHV/HHV-8 infection of human hematopoietic progenitor (CD34+) cells: Persistence of infection during hematopoiesis in vitro and in vivo. Blood 108, 141-151. doi: 10.1182/blood-2005-04-1697

Xu, N., Papagiannakopoulos, T., Pan, G., Thomson, J. A., and Kosik, K. S. (2009). MicroRNA-145 regulates OCT4, SOX2, and KLF4 and represses pluripotency in human embryonic stem cells. Cell 137, 647-658. doi: 10.1016/j.cell.2009.02.038

Zhang, J., Espinoza, L. A., Kinders, R. J., Lawrence, S. M., Pfister, T. D., Zhou, M., et al. (2012). NANOG modulates stemness in human colorectal cancer. Oncogene 32, 4397-4405. doi: 10.1038/onc.2012.461

Conflict of Interest Statement: The authors declare that the research was conducted in the absence of any commercial or financial relationships that could be construed as a potential conflict of interest.

Received: 01 August 2013; paper pending published: 05 September 2013; accepted: 03 December 2013; published online: 25 December 2013.

Citation: Iacovides D, Michael S, Achilleos C and Strati K (2013) Shared mechanisms in stemness and carcinogenesis: lessons from oncogenic viruses. Front. Cell. Infect. Microbiol. 3:66. doi: 10.3389/fcimb.2013.00066

This article was submitted to the journal Frontiers in Cellular and Infection Microbiology.

Copyright (๑) 2013 Iacovides, Michael, Achilleos and Strati. This is an open-access article distributed under the terms of the Creative Commons Attribution License (CC BY). The use, distribution or reproduction in other forums is permitted, provided the original author(s) or licensor are credited and that the original publication in this journal is cited, in accordance with accepted academic practice. No use, distribution or reproduction is permitted which does not comply with these terms. 